\title{
Programação em blocos com o Mit App Inventor: Um relato de experiência com alunos do ensino médio.
}

\author{
Natália Nascimento Leôncio', Claudiany Calaça de Sousa ${ }^{2}$, Rogério Pereira de Sousa ${ }^{3}$, \\ Ramásio Ferreira Melo 4 . \\ ${ }^{1}$ Acadêmica de Licenciatura em Computação - IFTO, Campus Araguatins. \\ ${ }^{2}$ Acadêmica de Licenciatura em Computação - IFTO, Campus Araguatins. \\ ${ }^{3}$ Mestre em Engenharia de Produção e Sistemas (UNISINOS) - Professor do IFTO, Campus \\ Araguatins. \\ ${ }^{4}$ Mestre em Educação (UFSM) - Professor do IFTO, Campus Araguatins.
}

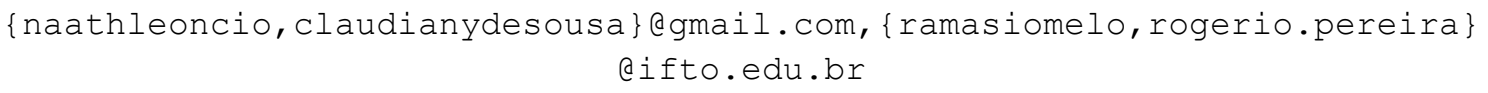

Abstract. This article presents an analysis of the use of MIT App Inventor in teaching programming logic in an interactive way, without previous cognitive knowledge in programming. During the study, we sought to investigate App Inventor's forms of mediation in learning, considering the interaction between the student and the platform. The research comes from the qualitative analysis of the mobile applications developed by the students in accordance with the contents passed during the block programming course, offered in the mobile laboratory of the open technical school network of Brazil $(e-T e c)$. The results analyzed allowed the positive visualization of the use of the platform as a facilitator of the teaching and learning process of the programming logic.

Resumo. Este artigo apresenta uma análise sobre o uso do MIT App Inventor no ensino da lógica de programação de forma interativa, sem que haja um conhecimento cognitivo prévio em programação. Durante o estudo, buscou-se investigar as formas de mediação do App Inventor na aprendizagem, considerando a interação entre aluno e a plataforma. A pesquisa provém da análise qualitativa das aplicações móveis desenvolvidas pelos alunos em conformidade com os conteúdos passados durante o curso de programação em blocos, ofertado no laboratório móvel da rede Escola técnica aberta do Brasil (e-Tec). Os resultados analisados permitiram a visualização positiva do uso da plataforma como facilitadora do processo de ensino e aprendizagem da lógica de programação.

\section{Introdução}

A lógica de programação é requisito básico para os cursos de computação, sendo um instrumento importante para a estruturação do raciocínio lógico e formulação de algoritmos. No entanto, nota-se que há uma certa dificuldade na aprendizagem dos alunos quando se trata da programação, lógica, matemática ou algoritmo. Segundo Soares et al. (2016) "essa dificuldade também é um dos principais motivos da evasão em cursos da área de Computação".

Segundo Gomes e Melo (2013), o processo de ensino da lógica de programação está interligado a diversos desafios que vai desde as dificuldades dos alunos na compreensão do problema proposto à os requisitos prévios necessários para um desempenho satisfatório na aprendizagem.

Para Kutzke e Direne (2013), este cenário complexo exige muito trabalho por parte dos professores e alunos no processo de ensino e aprendizagem e que, durante a aprendizagem, o aluno enfrenta sérias dificuldades que geram erros nos códigos criados, trazendo frustrações no desenvolvimento de aplicações e estudo da disciplina. 
O MIT App Inventor for Android ou App Inventor é uma plataforma de código aberto desenvolvida pela Google, e atualmente é mantida pelo Massachusetts Institute of Technology (MIT). Ela permite que recém- chegados à programação de computadores criem aplicações de software para o sistema operacional Android, sem que tenham um conhecimento prévio a respeito da área. Para Gomes e Melo (2013), esta plataforma possui um diferencial que consiste na possibilidade que os usuários têm na criação de aplicações que incorporam serviços baseados na web, interação com redes sociais, leitura de códigos de barra, geolocalização, dentre outras funcionalidades.

Mediante as dificuldades apresentadas, a utilização do MIT App Inventor proporciona uma visão mais lúdica e interativa da programação, pois seu ambiente gráfico possibilita o ensino de conceitos da lógica de programação de uma forma atraente e motivadora para estudantes do ensino médio Gomes e Melo, (2013).

Logo, este trabalho apresenta um relato de experiência sobre a utilização do App Inventor (AI) e suas contribuições em favor da aprendizagem da lógica de programação a partir dos projetos desenvolvidos durante as aulas do curso de programação em blocos da Rede E-Tec.

\section{Procedimentos metodológicos}

Desenvolveu-se um projeto pedagógico, no formato de curso introdutório de programação, com duração de 40 horas, oferecido para estudantes do $1^{\circ}$ ano do ensino médio da rede estadual do município, interessados na temática e que não tiveram a oportunidade de estudá-la formalmente.

O curso "Programação em blocos com App Inventor", foi ministrado por bolsistas do PIBID (Programa Institucional de Bolsas de Iniciação à Docência) - Subprojeto de Informática, do curso de Licenciatura em Computação. O curso ocorreu no Laboratório Móvel da Rede Etec, com a parceria da prefeitura municipal de Araguatins com o IFTO-Campus Araguatins.

A turma era composta por 15 alunos, conforme a capacidade de atendimento do laboratório móvel. As aulas transcorreram a partir de encontros semanais, com duração de 4h/aulas. O planejamento dessas aulas baseou-se nas seguintes etapas:

A $1^{\circ}$ etapa: consistiu no ensino do conceito de programação em blocos, abordando a sua lógica, seguida pela apresentação da plataforma do seu objetivo e funcionamento.

A $2^{\circ}$ etapa: consistiu na utilização da plataforma, de maneira prática, apresentando as ferramentas, recursos e componentes existentes. Nesse estágio os alunos puderam manipular menus, e telas, assimilando os elementos básicos presentes na programação.

A $3^{\circ}$ etapa: consistiu no ciclo mais duradouro de aulas, bem como o de maior relevância também, pois nele se conduziu o desenvolvimento de aplicações básicas juntamente com os professores.

A exposição das aplicações ocorreu por meio de explicações práticas e através de videoaulas disponíveis no Youtube, ambos para melhor compreensão da lógica de programação. No decorrer deste processo, foram elaborados 3 projetos: Manipulação de listas de tarefas, Calculadora de operações básicas e Calculadora de IMC.

A $4^{\circ}$ etapa: composta pelo desenvolvimento em grupo e individual de aplicações móveis, baseadas no conhecimento adquiridos na etapa anterior. Tais conhecimentos alicerçaram a produção em grupo de um GPS e de uma Calculadora de Juros compostos individualmente, ambos elaborados de forma independente entre os alunos.

Esta metodologia baseada na criação de pequenos projetos desenvolvidos ao longo do curso, proporcionou uma maior interação com a linguagem de programação, bem como o melhor acompanhamento da aprendizagem. Em todas atividades propostas, trabalhou-se a aprendizagem colaborativa para a criação dos aplicativos propostos, facilitando a troca de conhecimentos através do trabalho em grupo. Entre conteúdos práticos e teóricos, estimulouse a formação de alunos autodidatas, com o intuito de aprimorar a capacidade de raciocínio dos 
mesmos, encontrada também nos temas matemáticos de todos as aplicações, utilizando-os como sustento fundamental da lógica de programação.

Em harmonia com todas as etapas, fundamentou-se a análise de dados, a partir de uma abordagem qualitativa dos projetos desenvolvidos pelos alunos, buscando saber se os alunos conseguiram assimilar o conteúdo passado ao desenvolvimento de seus projetos, e se de fato, o uso da plataforma MIT App Inventor facilitou o aprendizado de lógica de programação.

\section{Resultados e discussões}

No decorrer das fases iniciais, pode-se notar pouca familiaridade por parte dos alunos a respeito da programação, além da falta de noção do que realmente poderiam aprender no curso. A medida que foram expostos os conceitos, utilidades, recursos e simplicidade na criação dos aplicativos, os estudantes passaram a se ambientar com esse novo universo lógico.

Outro fator colaborador para esta ambientação, foi o modelo de linguagem utilizada na plataforma. A linguagem utilizada é bem semelhante a linguagem Scratch, que também é um ambiente de programação desenvolvido pelo MIT, onde permite que os alunos arrastem e soltem objetos visuais (blocos) para criação de aplicativos.

Em conformidade com Soares et. al (2016) esta linguagem traz muitas possibilidades aos alunos, tais como "o desenvolvimento do raciocínio lógico e conceitos matemáticos que norteiam a programação de computadores visando uma interação mais acessível por meio do desenvolvimento de programas através de blocos que remetem ao LEGO1.”, (Figura 1).

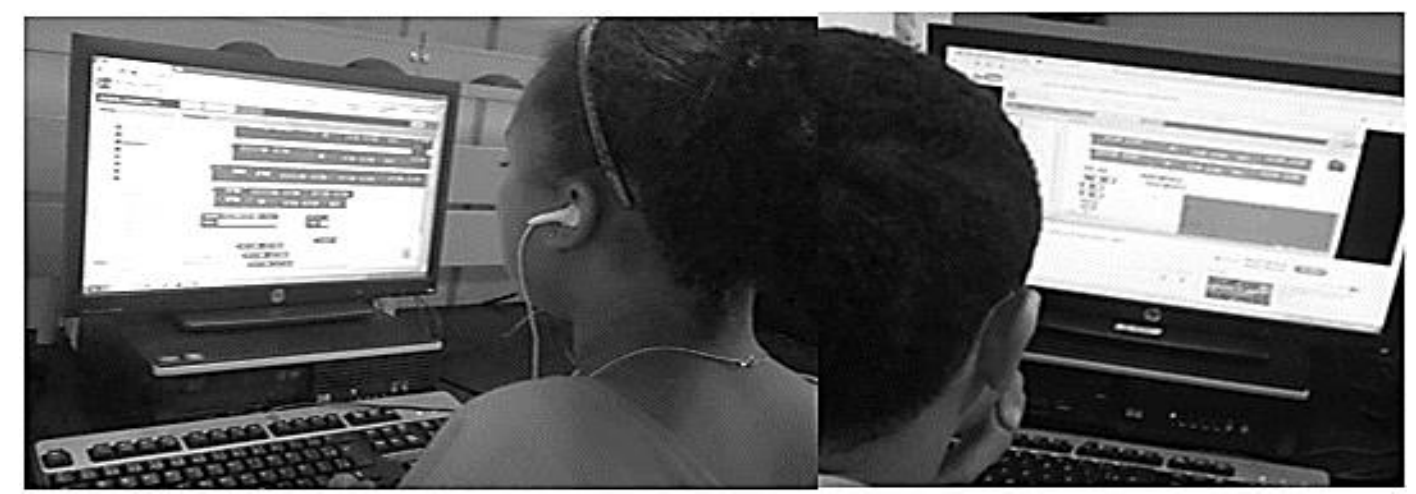

Figura 1. Fotos tiradas durante as aulas do curso de programação em blocos.

A partir da habituação dos alunos, com a ferramenta e com a programação em si, notouse a participação ativa de todos no processo de desenvolvimento dos projetos, assim como domínio imediato dos recursos presentes na plataforma.

Ao se iniciar a etapas de implantação de aplicativos mais complexos, todos os alunos conseguiram acompanhar o conteúdo e desenvolver os projetos conforme os requisitos apresentados. Tiveram também o potencial de inserir desde elementos básicos de layout até a montagem lógica da sequência blocos necessários para o funcionamento das aplicações. Mesmo nos casos de utilização de videoaulas para a criação dos projetos, todos foram capazes de finalizá-los sem muitas complicações no desenvolvimento (Figura 2 e 3 ). 
VI Congresso Brasileiro de Informática na Educação (CBIE 2017)

Anais do XXIII Workshop de Informática na Escola (WIE 2017)

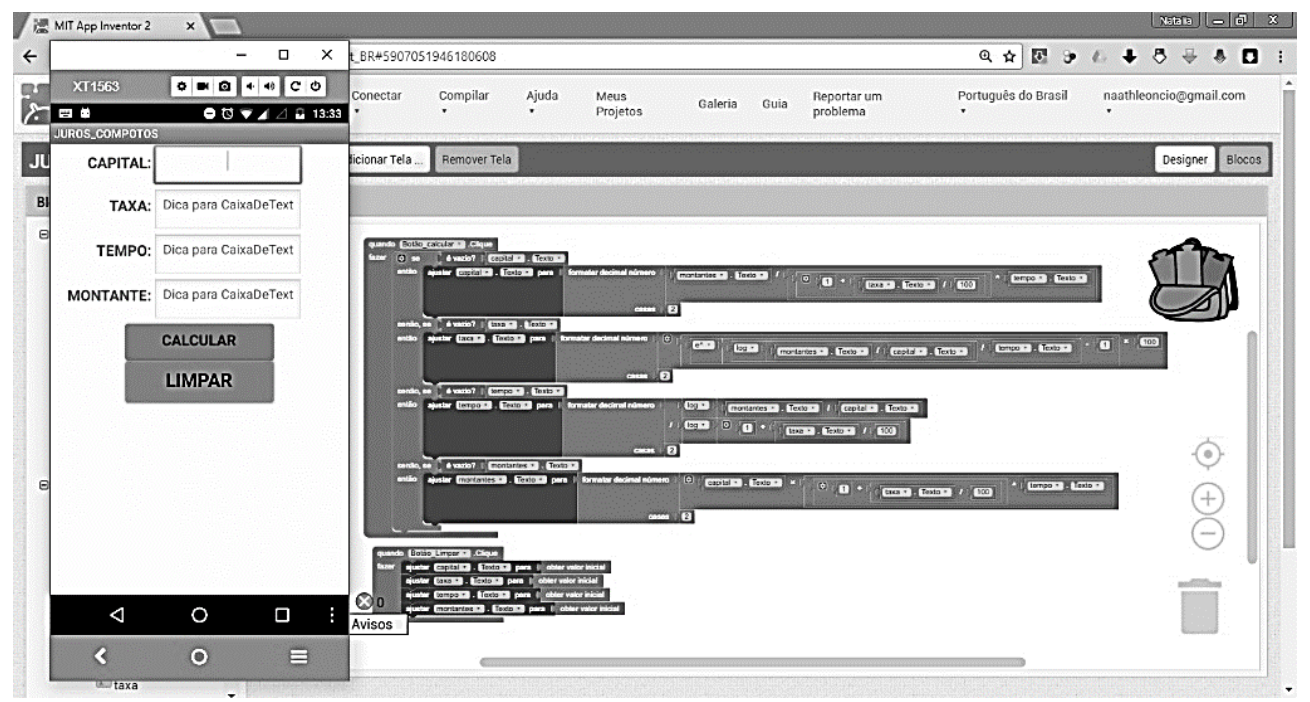

Figura 2. Aplicação desenvolvido durante as aulas do curso para calcular juros compostos.

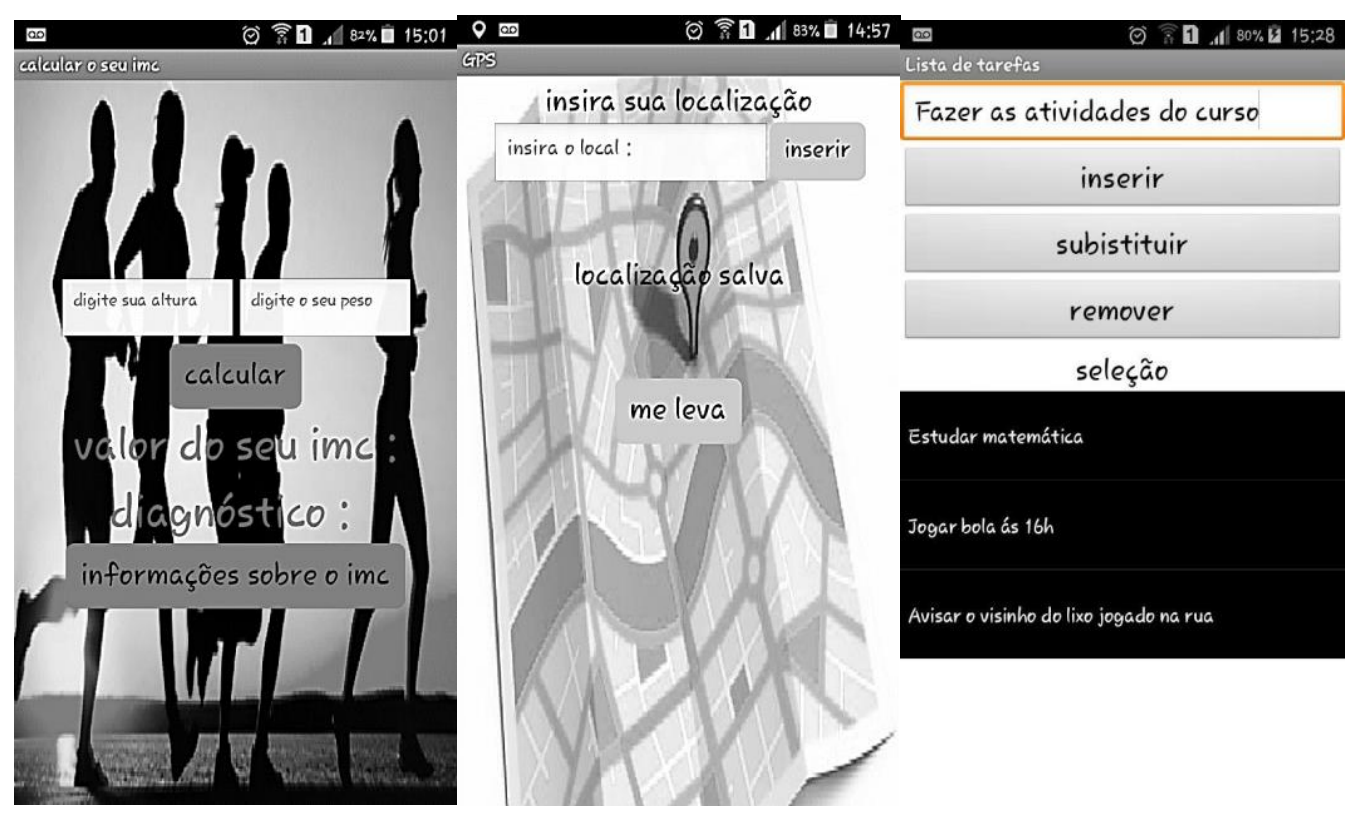

Figura 3. Tela principal de alguns aplicativos que foram desenvolvidos pelos alunos durante as aulas (IMC, GPS, Lista de tarefas).

Ao se iniciar a etapas de implantação de aplicativos mais complexos, todos os alunos conseguiram acompanhar o conteúdo e desenvolver os projetos conforme os requisitos apresentados. Tiveram também o potencial de inserir desde elementos básicos de layout até a montagem lógica da sequência blocos necessários para o funcionamento das aplicações. Mesmo nos casos de utilização de videoaulas para a criação dos projetos, todos foram capazes de finalizá-los sem muitas complicações no desenvolvimento.

Dentro das situações de criação independente, o compartilhamento de conhecimento em forma grupal, aproximou os alunos do mesmo modo que sanou as dúvidas e dificuldades que os mesmos possuíam. No fim da última etapa do curso, os alunos já eram capazes de desenvolver seus projetos sem grande interferência dos bolsistas nesse processo, conforme mostra a figura 4. 


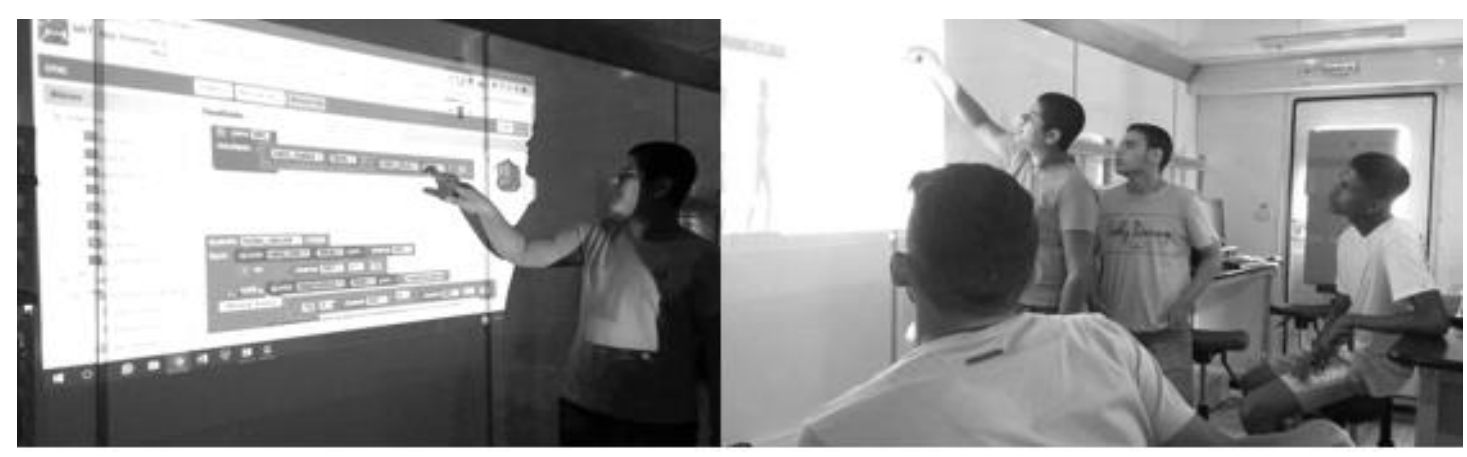

Figura 4. Fotos das aulas do curso de programação em blocos.

Ao trabalharem individualmente, contemplou-se o grau de aprendizagem de cada aluno. Neste aspecto, alguns possuíam um nível de conhecimento maior que os outros, entretanto todos foram capazes de concluir os aplicativos propostos com todas as funcionalidades presentes na proposta de criação.

\section{Conclusão}

O sucesso no desempenho dos alunos em suas aplicações, apenas confirmam os efeitos positivos do App Inventor no processo de aprendizagem, principalmente nos contatos iniciais com a programação. Diferente dos métodos tradicionais de ensino da programação, resumidos a sintaxes específicas e a saída dos resultados em uma tela preta ou com pouquíssimos recursos visuais, a ferramenta realmente apresenta grande diferencial: sua interface.

Outro diferencial apresentado pela ferramenta, consiste na própria programação voltada para a plataforma Android. Se comparada com outras plataformas de desenvolvimento, considerando o Android Studio por exemplo, que apesar de ser uma robusta ferramenta de programação, exige um maior conhecimento para sua manipulação. Distintivamente da plataforma trabalhada com os alunos, que facilita um primeiro contato com o desenvolvimento de aplicações, descomplicando a inserção de programadores iniciantes no universo lógico da programação.

Tanto no processo de desenvolvimento como no de execução das aplicações, a possibilidade de criar aplicativos à sua maneira própria é traz grande impacto nos estudos, pois não se limita apenas ao uso do computador, mas se estende até a usabilidade do que foi criado de maneira útil e acessível. Todo o potencial didático-pedagógico do App Inventor, torna-o um grande recurso que pode ser adotado em sala por professores, garantindo a prática da lógica de programação.

\section{Referências}

Gomes, Tanciscleide C. S., Melo, Jeane C. B. de. App Inventor for Android: Uma Nova Possibilidade para o Ensino de Lógica de Programação. II Congresso Brasileiro de Informática na Educação. Workshops (WCBIE 2013), p. 620-629.

Kutzke, Alexander Robert, Direne, Alexander Ibrahim. Mediação do erro no ensino de programação de computadores: fundamentos e aplicação da ferramenta FARMA-ALG. a. Anais dos Workshops do V Congresso Brasileiro de Informática na Educação (CBIE 2016), p. 1050-105.

Soares, Josiane P. R. dos Santos, Cercil, Rafael G., Monte-Alto, Helio H. L. C. Clube de programação e oficinas como Scratch: um relato de experiência. Anais dos Workshops do V Congresso Brasileiro de Informática na Educação (CBIE 2016), p. 958-962. 